\title{
A LOS OJOS RECTORALES
}

\author{
Eduardo González Mazo \\ Rector de la Universidad de Cádiz
}

"En Nuestra Defensa"

La decisión de editar la revista Rued@ (Revista Universidad, Ética y derechos) por parte de las Defensorías Universitarias constituye una herramienta de enorme conveniencia que, al unísono, permite materializar dos importantes objetivos: poner en valor el excelente trabajo que desempeñan estos órganos, imprescindibles en el democrático funcionamiento de nuestro sistema universitario, $\mathrm{y}$, desde el conocimiento sobre su labor, afianzar su mantenimiento en el actual modelo universitario español.

Mi agradecimiento, pues, a la directora de la Rued@, la Prof. ${ }^{\text {a }}$ Dr. ${ }^{a}$ María Acale Sánchez, Defensora de la Universidad de Cádiz, por la invitación a participar en este foro y por impulsar, desde el principio, la creación y puesta en marcha de este nuevo medio de expresión, especializado, donde convergen la acción de nuestras Defensorías, necesitadas de este tipo de puntos de encuentros para intercambiar ideas, experiencias y conocimientos.

Las Defensorías Universitarias rinden un servicio fundamental a nuestras universidades. Hacen de parapeto y de salvaguarda, son un engranaje adecuado para ejercer la mediación, tanto formal como informal, y se presentan como una instancia imprescindible para la consulta y defensa de los derechos de nuestras comunidades universitarias. Por eso, deben verter su rigor y actividad al servicio del conjunto de 
nuestras comunidades universitarias: Personal Docente Investigador, Personal de Administración y Servicios y Alumnado.

Para el buen desarrollo de sus trabajos y cometidos, en sus acciones deben estar representados los tres estamentos universitarios con la creación, por ejemplo, de defensores/as adjuntos/as de estudiantes. Es ésta una cuestión que ha esgrimido la propia Universidad de Cádiz, en cuya Defensoría Universitaria se prevé que estén orgánicamente representados profesores, personal de administración y alumnado.

Una idea cabal de la dimensión de Rued@ podemos observarla en la diversidad y calado de los temas tratados en el número cero: causas de los resultados anómalos en las asignaturas, copia, plagio y fraude en la evaluación universitaria, anulación de matrículas y devolución de importes, etc. El vértigo de las responsabilidades y cometidos diarios nos inhibe en muchas ocasiones de la opción elemental de pensar. La necesidad inaplazable de decidir y de gestionar nuestras instituciones universitarias, inmersas en un acelerado proceso de transformación, nos impide pararnos y tomar la perspectiva suficiente como para reflexionar acerca de cómo hacemos las cosas.

Aquí incide la utilidad de Rued@. La reflexión, el pensamiento crítico y con calma, el análisis pausado sobre la praxis de nuestras universidades en temas de indiscutible importancia como los abordados en este primer número, o el estudio realizado desde el rigor y la responsabilidad son motivos suficientes para resaltar el valor de una publicación que es nexo de unión, de entendimiento y conocimiento entre todas las Defensorías Universitarias españolas.

En nuestra acción, debe prevalecer siempre la exigencia de velar por el respeto a los derechos y las libertades de toda la comunidad universitaria (profesores, estudiantes y personal de administración y servicios), ante las actuaciones de los diferentes órganos y servicios universitarios. A tal efecto, la legislación universitaria -tanto la Ley Orgánica 
de Universidades como la correspondiente Ley andaluza- prevén la creación de Defensorías Universitarias.

De este modo, los Estatutos de la Universidad de Cádiz dedican el Título IV a esta esencial figura universitaria, encomendándosele una misión garantista del bienestar de los miembros de la comunidad universitaria. Sus acciones están siempre dirigidas hacia la mejora de la calidad universitaria en todos sus ámbitos, sin mediar jamás en sus actuaciones mandato imperativo de ninguna instancia universitaria, rigiéndose por los principios de independencia, autonomía e imparcialidad.

Sin duda, las Defensorías Universitarias realizan una extraordinaria labor de mediación y buenos oficios en la resolución de los conflictos que se suscitan en el ámbito universitario. Median, sugieren, recomiendan, desde una posición imparcial y garantista. Gozan de prestigio y de un incuestionable carácter autónomo en la defensa de los derechos y libertades, lo que implica, de modo ineludible, aunque no se diga expresamente en la citada normativa, velar por el cumplimiento de los deberes.

Un trabajo ímprobo ejercido con libertad y responsabilidad en defensa de todos los integrantes de nuestras comunidades universitarias que, así, encuentran en sus Defensorías un instrumento para garantizar sus derechos y la resolución de conflictos desde la mediación, el rigor y el conocimiento de nuestros derechos y deberes.

La Rued@ permitirá que las Defensorías Universitarias españolas estrechen lazos y pongan en común informes y estudios acerca de su labor y que el conjunto de nuestras comunidades universitarias dispongamos, al mismo tiempo, de un medio para conocer todo lo bueno y lo mucho que hacen. Más Defensoría y más información sobre sus cometidos y actuaciones es sinónimo de más democracia para el funcionamiento de nuestro sistema universitario. 
Afirmaba con intachable determinación ética Francisco Tomás y Valiente, catedrático de Historia del Derecho, que "la vida y el prestigio de las instituciones depende tanto de lo que ellas hacen como de lo que se hace con ellas". Con la creación, generalización y consolidación de las Defensorías Universitarias incidimos, precisamente, en esto: en hacer de nuestras universidades unas instituciones más garantes, más fuertes y democráticas. 